\title{
Un diagnóstico sobre cadáveres sin identificar (nn) producto del conflicto armado, registrados e inhumados en cementerios del oriente antioqueño.
}

\author{
A Diagnosis About Unidentified Corpses as a Product of the Armed Conflict, \\ Registered and Buried in Cemeteries of The Western Region of Antioquia.
}

\section{Resumen:}

este artículo presenta los resultados de la investigación "Oriente, Memoria Desenterrada, un Camino para la Identificación de Personas Desaparecidas en el Oriente Antioqueño", donde se presenta un diagnóstico cualitativo y cuantitativo pionero en Colombia, hasta donde se conoce, sobre las condiciones del registro y disposición final de cadáveres no identificados (NNs) en cementerios, con una delimitación temporal de enero de 1985 hasta junio de 2008, con el ánimo de sacar a la luz la situación histórica y social de esta problemática.

La exploración apunta finalmente a dar cuenta del fenómeno de la desaparición forzada de personas; propone un conjunto de prácticas adecuadas con cadáveres no identificados, a ser tenidas en cuenta en los despachos parroquiales y en los cementerios. Así mismo aporta elementos para la construcción de una cultura de paz.

\section{Palabras Claves:}

antropología, cadáveres no identificados (N.N), conflicto armado en el Oriente antioqueño, desaparición forzada de personas, investigación social, muertes violentas, NNs.

\section{Abstract:}

This article shows the results of the research entitled "West, an Unburried Memory, a Road for the Identification of Missing People in the Western Region of Antioquia." Where it is shown a qualitative and quantitative diagnosis, which is a pioneering diagnosis in Colombia, as far as it is known, about the conditions of the registration and final disposal of unidentified corpses in cemeteries, within a range period of time, from January 1985 to June 2008, in order to bring the historic and social situation of this issue to light.

This research aims at giving an account of the phenomenon of the forced disappearance of people, and it proposes a set of adequate practices with unidentified corpses, to be taken into account in parochial offices and in cemeteries. As well, it provides some elements for the construction of a culture of peace.

\section{Key words:}

Anthropology, unidentified bodies, armed conflict in the Western region of Antioquia, forced disappearance of people, social research, violent deaths.

\footnotetext{
'Antropólogo de la Universidad de Antioquia. Investigador social en temas de violencia, conflicto armado colombiano, Derechos Humanos y Derecho Internacional Humanitario. Coordinador de la investigación Oriente, Memoria Desenterrada, un Camino para Identificar Personas Desaparecidas en el Conflicto Armado en el Oriente Antioqueño, 2008. Docente de cátedra del departamento de Antropología de la Universidad de Antioquia. juanjosemoncada@gmail.com
} 


\section{Introducción}

En el marco del Segundo Laboratorio de Paz en Colombia, región del Oriente Antioqueño, el proyecto Observatorio de Paz y Reconciliación avanzó, entre febrero de 2006 y diciembre de 2008 , en la investigación, seguimiento y análisis de la situación social y políitica de esa región, en tres ejes estructurales: desarrollo económico, gobernabilidad democrática y Derechos Humanos y Derecho Internacional Humanitario.

Con el objetivo de conocer el escenario de los Derechos Humanos y el Derecho Internacional Humanitario, tanto en lo que acontecía permanentemente como en la situación histórica de la región ${ }^{2}$, se propone la realización de un monitoreo sobre la condiciones del registro y disposición final de cadáveres sin identificar (NN) en los cementerios, así como la exploración del fenómeno de la desaparición forzada de personas y las exhumaciones de fosas comunes. De esta forma surge una investigación de carácter exploratorio, puesto que no se conoce hasta el momento algo similar en Colombia.

Se realiza entonces la investigación titulada "Oriente, Memoria Desenterrada, un Camino para Identificar Personas Desaparecidas en el Conflicto Armado en el Oriente Antioqueño". Esta investigación cuenta con una metodología propia, construida a medida que se adelantaba la búsqueda de hechos. Además dispone en su totalidad de fuentes de información primarias, es decir, oficiales y eclesiásticas.

\section{1. ¿Por qué identificar a estas personas?}

Muchas razones son valederas para dar respuesta a este interrogante. La primera se refiere a la necesidad de sanación de toda la sociedad; cada persona no identificada es un/a desaparecido/a, y por lo tanto hay una familia esperando su regreso o queriendo conocer dónde se encuentra, sea vivo o fallecido. Dada la gran cantidad de personas desaparecidas en Colombia, toda la sociedad necesita sanar el dolor infligido y realizar el duelo.

De la misma manera las víctimas del conflicto armado requieren conocer las verdades de los hechos, que se haga justicia frente a eso y que, de alguna manera, se repare la condición en que han quedado. En cuanto a la verdad, que es lo más solicitado por las familias, se espera conocer el paradero de los seres queridos y así trascender su condición de víctimas a ciudadanos con dignidad y con capacidades de decisión y transformación de sus vidas.

${ }^{2}$ Compuesta por veintitrés municipios: Abejorral, Alejandría, Argelia, Cocorná, Concepción, El Carmen de Viboral, El Peñol, El Retiro, El Santuario, Granada, Guarne, Guatapé, La Ceja, La Unión, Marinilla, Nariño, Rionegro, San Carlos, San Francisco, San Luis, San Rafael, San Vicente y Sonsón. 
Por último, realizar un programa amplio de identificación de estas personas aporta a la generación de cultura de paz en Colombia, que consiste en una serie de valores, actitudes y comportamientos que rechazan la violencia, previene los conflictos entendiendo y superando sus causas, y solucionando los problemas mediante el diálogo y la negociación. La cultura de paz también tiene relación con la necesidad de un cambio de los valores morales de toda la sociedad donde sea profundamente valiosa la presencia del otro con su vida y su dignidad y donde prime el respeto a la vida antes que las diferencias políticas e ideológicas.

\section{Metodología.}

La pregunta inicial sobre hasta dónde llega el fenómeno de desaparición forzada de personas en el Oriente Antioqueño plantea otra de igual importancia: ¿̇uántos de los cadáveres que reposan en los cementerios de la región carecen de identidad?

Este tránsito de cuestiones se hace porque los cadáveres sin identificar pueden ser cuantificables de manera objetiva dada la materialidad del hecho y la disposición de abundante fuente documental oficial, pero ante todo porque se tiene la convicción de que en esos restos mortales se halla la evidencia para ubicar el paradero de numerosas personas desaparecidas, y porque, en últimas, cada uno de esos cadáveres representa la historia de una búsqueda familiar o de un dolor que no cesa.

Para abordar esta investigación se estableció la delimitación temporal de enero de 1985 a junio de 2008. En 1985 ya estaban presentes en el Oriente antioqueño todos los actores en armas: guerrillas, paramilitares, Fuerza Pública y fuerzas del narcotráfico; en junio de 2008 finalizó el trabajo de campo. Dado que no se conoce una investigación de estas características, se propone una metodología inicial llamada "Cadena de registro y disposición final del cadáver". En un primer momento parecía apenas lógico que había una cadena coherente de registro y disposición final, con tres eslabones consecutivos.

El primer eslabón: cuando se halla el cadáver de una persona, se lleva a cabo una diligencia de levantamiento; el resultado debía ser un acta de levantamiento o inspección de cadáver teniendo en cuenta que las Inspecciones de Policía realizaron los levantamientos hasta el 31 de diciembre de 2006 en Antioquia; a partir del 1 de enero de 2007, en el marco del nuevo sistema penal acusatorio, se encomendó esta labor a la Policía Judicial-.

El segundo: luego del levantamiento, el cadáver es dirigido al cementerio y para ello es necesario registrarlo en el libro de defunciones del despacho parroquial que administra el cementerio de la localidad; el resultado debía ser un número o código de registro en dicho libro. 
Tercer eslabón: una bóveda o sepultura (con una lápida debidamente marcada) donde reposa el cadáver; en este caso, los cuerpos con más de cuatro o cinco años de antigüedad no estarían en las bóvedas por cuanto al llegar ese tiempo sus restos óseos son llevados a los osarios comunes; en consecuencia, en el cementerio se contaría, además de las lápidas marcadas, con algún libro o cuaderno de registro de esos cadáveres, tanto los que aún permanecían, como los que fueron trasladados a osarios comunes.

De acuerdo a la anterior secuencia, un cadáver sin identificar debía contener un número de acta de levantamiento, un número de registro en el libro de defunciones de la parroquia y un número de bóveda en la cual está o estuvo inhumado. Pero no se trataba simplemente de cuantificar los hechos sino de conocer las características de ellos y así avanzar hacia un diagnóstico cualitativo; es por ello que se establece un listado de variables que dan cuenta de esa situación, como por ejemplo: el número de acta de inspección del cadáver, fecha de la inspección, lugar de la muerte, fecha presunta de la muerte, sexo de la víctima, posibles causas de la muerte, descripción física de la persona y más. En los libros de defunciones de las parroquias y en cementerio se documenta el nombre de la galería o pabellón de bóvedas, el número de la bóveda y la fecha de inhumación.

Se inicia entonces un riguroso trabajo de campo en el que se visitan todas las inspecciones de policía; de ellas se obtuvo información en veinte municipios y en tres corregimientos ${ }^{3}$; sólo en los municipios de El Santuario, Nariño y Rionegro no brindan la información. De otra parte, se visitan veinticuatro parroquias que administran todos los cementerios municipales del Oriente Antioqueño (Rionegro cuenta con dos) y nueve parroquias en corregimientos. En cuanto a cementerios, se visitan la totalidad: veinticuatro en municipios, nueve en corregimientos y uno veredal. ${ }^{4}$

La siguiente fase consiste en la sistematización, análisis y contrastación de los datos obtenidos en las fuentes de información consultadas. Pero la realidad encontrada expone una situación bastante compleja.

\footnotetext{
${ }^{3}$ Aquitania (San Francisco), El Jordán (San Carlos), El Prodigio (San Luis), La Danta (Sonsón), Mesopotamia (La Unión), Pantanillo (Abejorral), Puerto Venus (Nariño), San Miguel (Sonsón) y Santa Ana (Granada).

${ }^{4}$ Vereda San Isidro, municipio de San Francisco.
} 


\section{Resultados}

Al analizar y sistematizar los hechos se advierte que pocos formatos de actas de levantamiento tienen diligenciados todos los campos con las variables que se buscan, los registros en libros de defunciones son inconsistentes y en la mayoría de cementerios no se realiza una disposición adecuada de esos cadáveres. Pero de nuevo, otra realidad aún más confusa se puede observar al contrastar los registros entre las tres fuentes de información; la confusión había llegado, la coherencia no tenía lugar. Se encuentran situaciones como estas:

\section{Tabla 1:}

inconsistencias en el contraste de Registros: Acta de inspección, numero de registro y número de bóveda.

\begin{tabular}{|c|c|c|c|}
\hline \multicolumn{4}{|c|}{$\begin{array}{l}\text { 1. Hay acta de levantamiento, no hay registro en el libro de defunciones, pero el } \\
\text { cadáver está en una bóveda del cementerio ? }\end{array}$} \\
\hline \multicolumn{4}{|c|}{ Municipio de La Unión } \\
\hline $\begin{array}{l}\text { Fecha presunta de } \\
\text { muerte }\end{array}$ & $\begin{array}{l}\text { Inspección: } \\
\text { número acta de } \\
\text { inspección }\end{array}$ & $\begin{array}{l}\text { Parroquia: número } \\
\text { de registro }\end{array}$ & $\begin{array}{l}\text { Cementerio: número } \\
\text { de bóveda }\end{array}$ \\
\hline 9-febrero-2006 & 03 & Sin registro & 213 \\
\hline \multicolumn{4}{|c|}{$\begin{array}{l}\text { 2. No hay acta de levantamiento, pero sí registro en el libro de defunciones, sin } \\
\text { embargo no se encuentra la respectiva bóveda en el cementerio: }\end{array}$} \\
\hline \multicolumn{4}{|c|}{ Municipio de Granada } \\
\hline $\begin{array}{l}\text { Fecha presunta de } \\
\text { muerte }\end{array}$ & $\begin{array}{l}\text { Inspección: número } \\
\text { acta de inspección }\end{array}$ & $\begin{array}{l}\text { Parroquia: número } \\
\text { de registro }\end{array}$ & $\begin{array}{l}\text { Cementerio: número } \\
\text { de bóveda }\end{array}$ \\
\hline 28-marzo-2006 & Sin registro & folio 054 No 107 & Sin registro \\
\hline \multicolumn{4}{|c|}{$\begin{array}{l}\text { 3. No tiene acta de levantamiento ni registro en el libro de defunciones, pero, } \\
\text { extrañamente, el cadáver está en el cementerio. }\end{array}$} \\
\hline \multicolumn{4}{|c|}{ Municipio de Argelia } \\
\hline $\begin{array}{l}\text { Fecha presunta de } \\
\text { muerte }\end{array}$ & $\begin{array}{l}\text { Inspección: número } \\
\text { acta de inspección }\end{array}$ & $\begin{array}{c}\text { Parroquia: número } \\
\text { de registro }\end{array}$ & $\begin{array}{c}\text { Cementerio: número } \\
\text { de bóveda }\end{array}$ \\
\hline $11-$ dic-2001 & Sin registro & Sin registro & 184 \\
\hline
\end{tabular}

Fuente: base de datos investigación cadáveres sin identificar (NN) producto del conflicto armado, registrados e inhumados en cementerios del oriente antioqueño. 1985 al 2008

${ }^{5}$ Esta situación se presenta a pesar de que la legislación colombiana la regula desde hace casi un siglo: "Ley 66 de 1916: el administrador del cementerio no permitirá la inhumación de cadáveres sin esta licencia que deberá conservarse cuidadosamente en el archivo de la administración del cementerio". 
Queriendo aclarar las inconsistencias en los registros de hechos se procede a una nueva búsqueda de datos, en esta ocasión mucho más amplia, de manera que pueda llenarse los vacíos en la información. Esta etapa consiste en buscar los registros de cadáveres sin identificar en los hospitales municipales (con acta de necropsia), en notarías y registradurías (con registro civil de defunción), en el Cuerpo Técnico de Investigación (CTI) de la Fiscalía en Medellín (con número de acta de inspección) y en las Fiscalías Seccionales en los municipios (con números de registro o acta de inspección). De nuevo se quiere ir más allá de la cuantificación de hechos, se trata de fortalecer el diagnóstico cualitativo. En este orden de situaciones se prepara un nuevo listado de variables que den cuenta de esa condición en cada fuente de información.

En esta oportunidad el trabajo de campo cubre veinte hospitales del Oriente; sólo en los municipios de Abejorral, La Ceja y Rionegro no aportan información. También se consultan los hospitales de los corregimientos de La Danta y San Miguel en Sonsón. En cuanto a registradurías se accede a las veintitrés oficinas de la región y a diecinueve notarías (cuatro municipios no cuentan con esta dependencia), y las Fiscalías Seccionales de La Ceja y Marinilla. Así mismo, se cuenta con información del CTI de la Fiscalía en Medellín.

De nuevo, al analizar y sistematizar los recientes hechos se observa que, al igual que en la primera fase de búsqueda de información, las fuentes consultadas también eran incongruentes. Las inconsistencias que se querían aclarar resultaron aún más amplias. La confusión es total, la Cadena de registro y disposición final de cadáveres es cualquier cosa, menos una cadena. Una muestra aleatoria expone esta situación:

\section{Tabla 2:}

inconsistencias en la cadena de registro de cadáveres.

\begin{tabular}{|c|c|c|c|c|c|c|c|}
\hline \multicolumn{8}{|c|}{ Municipio de Argelia } \\
\hline $\begin{array}{l}\text { Regis- } \\
\text { tro }\end{array}$ & $\begin{array}{l}\text { Fecha } \\
\text { presunta de } \\
\text { muerte }\end{array}$ & $\begin{array}{l}\text { Inspección: } \\
\text { número } \\
\text { acta de } \\
\text { inspección }\end{array}$ & $\begin{array}{l}\text { CTI de la } \\
\text { Fiscalía: } \\
\text { número } \\
\text { acta de } \\
\text { inspección }\end{array}$ & $\begin{array}{l}\text { Hospital: } \\
\text { número } \\
\text { acta de } \\
\text { necropsia }\end{array}$ & $\begin{array}{l}\text { Registraduría: } \\
\text { número } \\
\text { indicativo } \\
\text { serial }\end{array}$ & $\begin{array}{l}\text { Parroquia: } \\
\text { número } \\
\text { de } \\
\text { registro }\end{array}$ & $\begin{array}{c}\text { Cementerio: número } \\
\text { de bóveda }\end{array}$ \\
\hline 1 & 12-jul-03 & s. r. ${ }^{*}$ & 1637 & s. r. & s. r. & s. r. & s. $r$. \\
\hline 2 & 30-ago-03 & 16 & s. r. & s. $r$. & s. r. & s. $r$. & s. $r$. \\
\hline 3 & 6-dic-03 & s. r. & s. $r$. & s. r. & 3723065 & 82 & 80 \\
\hline 4 & 11 -feb-04 & s. $r$. & 13 & s. r. & s. r. & s. r. & s. r. \\
\hline 5 & 6-may-04 & 17 & s. $r$. & 17 & 3743721 & 124 & 183 \\
\hline 6 & 26-oct-04 & 32 & s. r. & 32 & 3743741 & 166 & 152 \\
\hline 7 & 21-nov-04 & s. r. & s. r. & s. r. & 3743730 & s. r. & s. r. \\
\hline 8 & 22-nov-04 & s. r. & 2 & 52 & 3743780 & s. r. & s. r. \\
\hline 9 & 9-jun-05 & s. r. & s. r. & s. r. & s. r. & s. $r$. & 105 \\
\hline 10 & 15-ene-08 & 2 & s. $r$. & 2 & s. r. & 331 & 95 \\
\hline
\end{tabular}

Fuente: base de datos investigación cadáveres sin identificar (NN) producto del conflicto armado, registrados e inhumados en cementerios del oriente antioqueño. 1985 al 2008. •

s. $r .=$ sin registro. 
Ningún municipio del Oriente posee una cadena completa de registro y disposición final de cadáveres sin identificar. En el conjunto de datos, un municipio como Granada da cuenta de ese escenario:

Gráfico 1. Inconsistencias en la cadena de registro de cadáveres. Municipio de Granada.

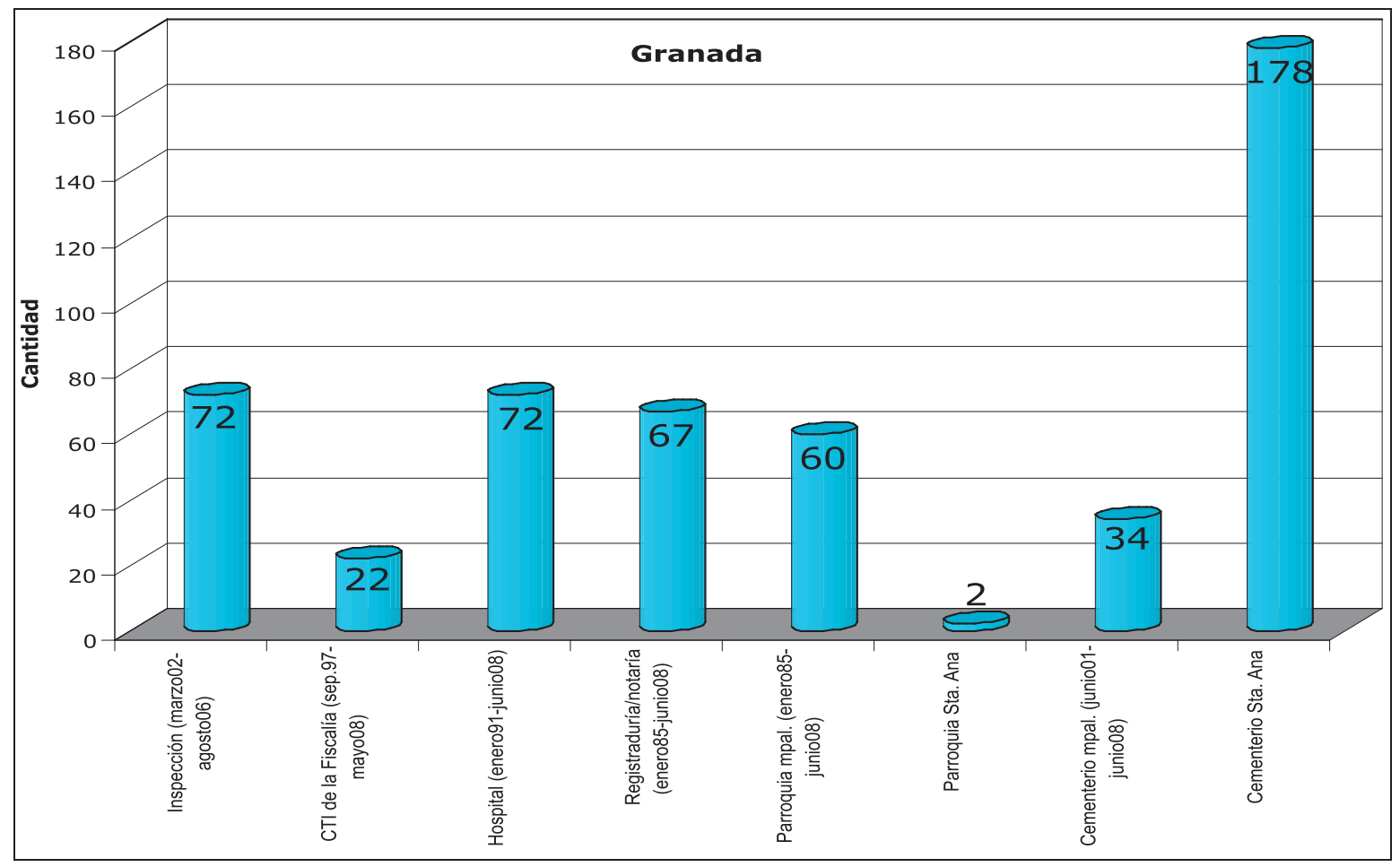

Fuente: base de datos investigación cadáveres sin identificar (NN) producto del conflicto armado, registrados e inhumados en cementerios del oriente antioqueño. 1985 al 2008.

Veamos: mientras que en la Inspección de Policía registraban 72 hechos, el CTI de la Fiscalía contaba con 22, pero sólo 2 coinciden entre una fuente y otra, los demás son diferentes. Entre la Inspección de Policía y el hospital las cifras de hechos son similares (72), pero al contrastar cada registro se encuentra concordancia sólo en 42 casos. Cuando se contrastan los registros entre hospital (72) y registraduría/notaría (67) se encuentra coincidencia sólo en 36 casos.

En cuanto a la registraduría y notaría (67 casos) respecto al despacho parroquial (60 casos) hay coincidencia en 36 de ellos. De los casos registrados en el libro de defunciones de la parroquia, escasamente se tenía inscripción de 24 en el cementerio. Nos asiste entonces la inquietud de dónde se encuentran los demás cadáveres. 
Al dar una mirada panorámica a todas las fuentes de información que fueron abordadas se evidencia que difícilmente se puede hablar que exista un procedimiento estándar para el registro de cadáveres, tanto identificados como NNs; y aún más preocupante es la disposición final de esos cadáveres. Las inconsistencias son lo único constante.

Para todo el Oriente del Departamento, en el periodo temporal de enero de 1985 a junio de 2008, se encuentra la cifra de 2.539 cadáveres no identificados. Y esto en una sola subregión de Antioquia ¿̇Qué sucederá entonces en el resto del Departamento y del país? Lo cierto, por ahora, es que aún hay muchas verdades por desenterrar y el siguiente paso debe ser la búsqueda de la identidad plena de esas personas.

Esta es la situación global en los municipios del Oriente Antioqueño entre 1985 y 2008 :

Tabla 3. Cadáveres no identificados por municipio del oriente Antioqueño.

\begin{tabular}{|c|c|c|}
\hline Municipio & Cantidad & Porcentaje \\
\hline Abejorral & 78 & $3,1 \%$ \\
\hline Alejandría & 32 & $1,3 \%$ \\
\hline Argelia & 57 & $2,3 \%$ \\
\hline Cocorná & 190 & $7,5 \%$ \\
\hline Concepción & 15 & $0,6 \%$ \\
\hline El Carmen de Viboral & 78 & $3,1 \%$ \\
\hline El Peñol & 27 & $1,1 \%$ \\
\hline El Retiro & 39 & $1,5 \%$ \\
\hline El Santuario & 66 & $2,6 \%$ \\
\hline Granada & 338 & $13,4 \%$ \\
\hline Guarne & 79 & $3,1 \%$ \\
\hline Guatapé & 26 & $1,0 \%$ \\
\hline La Ceja & 55 & $2,2 \%$ \\
\hline La Unión & 108 & $4,3 \%$ \\
\hline Marinilla & 95 & $3,8 \%$ \\
\hline Nariño & 56 & $2,2 \%$ \\
\hline Rionegro & 316 & $12,5 \%$ \\
\hline San Carlos & 174 & $6,9 \%$ \\
\hline San Francisco & 118 & $4,7 \%$ \\
\hline San Luis & 231 & $9,1 \%$ \\
\hline San Rafael & 90 & $3,6 \%$ \\
\hline San Vicente & 67 & $2,7 \%$ \\
\hline Sonsón & 204 & $7,5 \%$ \\
\hline TOTAL & $\mathbf{2 . 5 3 9}$ & $\mathbf{1 0 0 , 0 \%}$ \\
\hline
\end{tabular}

Fuente: base de datos investigación cadáveres sin identificar (NN) producto del conflicto armado, registrados e inhumados en cementerios del oriente antioqueño. 1985 al 2008. 


\subsection{La identidad social de los cadáveres NN.}

Un hallazgo del trabajo de campo que llama fuertemente la atención es lo que se denominó "identidad social de los cadáveres NN". Los testimonios de sepultureros, párrocos y familiares de víctimas exponen numerosos casos donde conocen los nombres reales de personas sepultadas sin identidad.

Esta situación se manifestó en los momentos más álgidos del conflicto armado cuando las familias de algunos NNs no podían reconocer a sus seres queridos por temor a la amenaza y represalias de actores armados. Los testimonios indican que por ser parientes de una determinada persona, los integrantes del grupo enemigo señalaban, estigmatizaban y asesinaban a quienes tuviesen parentesco con la persona muerta. En otros casos los sepultureros y sacerdotes conocen la identidad real de algunos $N N$ pero no encontraban en su momento a un familiar que asumiera la responsabilidad frente a las autoridades judiciales. De otro lado están las tumbas que a pesar de tener el registro de NN en su lápida alguien le lleva flores periódicamente (ver fotografía); esta situación se repite en muchos cementerios visitados.

Foto 1: Bóveda de $\mathrm{NN}$ en el cementerio de El Retiro.

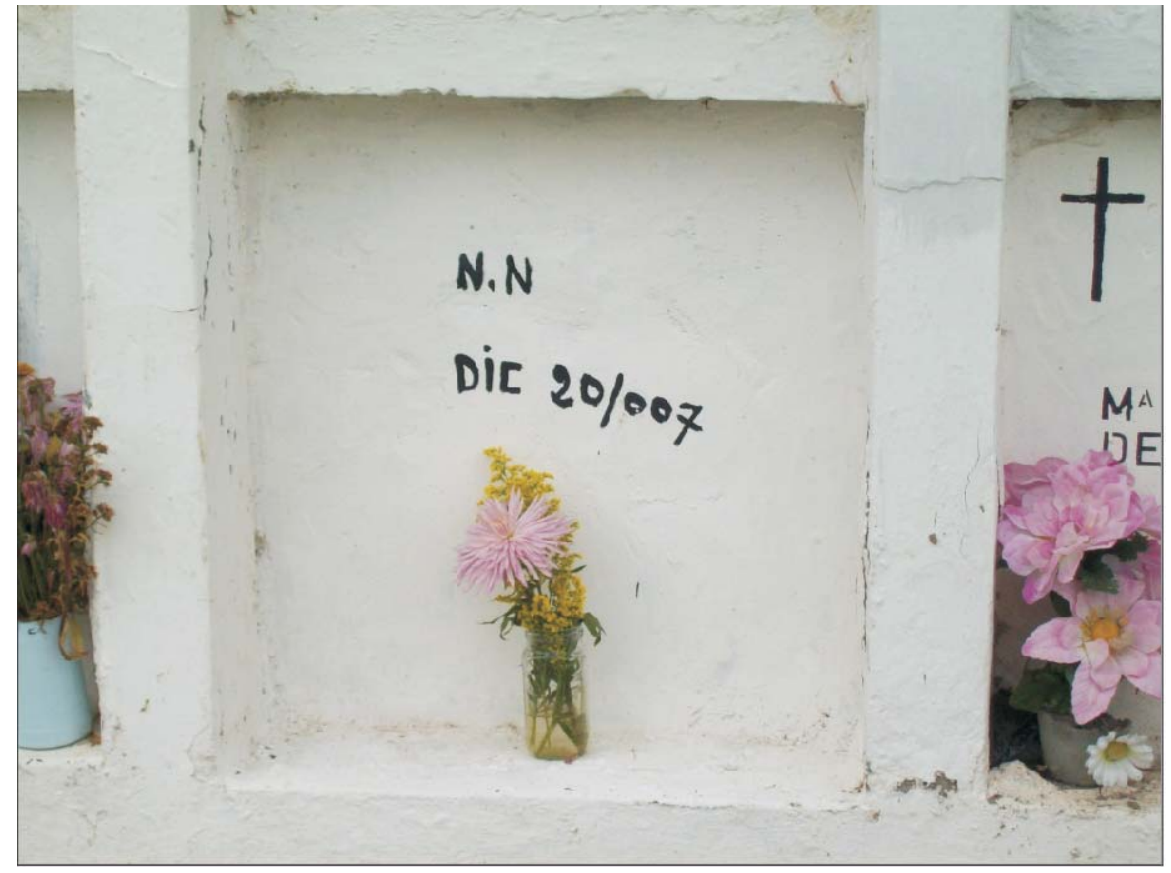

Fuente: Archivo fotográfico Investigación cadáveres sin identificar (NN) producto del conflicto armado, registrados e inhumados en cementerios del oriente antioqueño. 1985 al 2008. 
Otra muestra de "identidad social" es aquella cuyas lápidas poseen un nombre o alias; en algunas se puede leer "NN Carlos" o "NN Emerson", como muestra la siguiente fotografía. De éste último alias, el sepulturero del municipio de Alejandría narra que un cadáver NN "tenía un papelito en el bolsillo del pantalón con ese nombre 'Emerson' y lo escribí en la lápida pa' ver si alguien lo reconoce algún día".

Foto 2: Bóveda de $\mathrm{NN}$ en el cementerio de Alejandría.

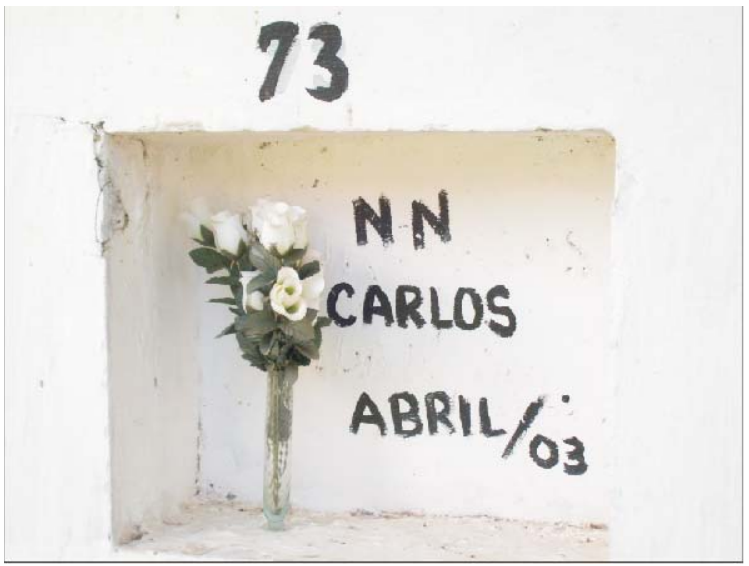

Fuente: Archivo fotográfico Investigación cadáveres sin identificar (NN) producto del conflicto armado, registrados e inhumados en cementerios del oriente antioqueño. 1985 al 2008.
Foto 3: Bóveda de NN en el cementerio de Alejandría.

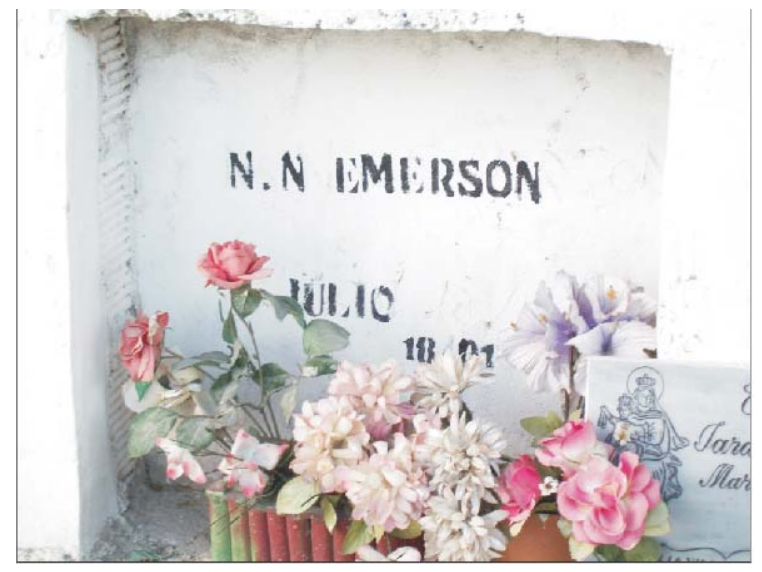

Fuente: Archivo fotográfico Investigación cadáveres sin identificar (NN) producto del conflicto armado, registrados e inhumados en cementerios del oriente antioqueño. 1985 al 2008.

Es importante anotar que la identidad plena o judicial de una persona la otorgan únicamente instituciones del Estado como Medicina Legal o la Fiscalía, y a partir de allí se expide un certificado civil de defunción; en caso de no presentarse estas condiciones, el cadáver es considerado NN.

\section{Conclusiones - Propuesta}

\subsection{Propuestas sobre prácticas adecuadas con cadáveres no identificados.}

Una investigación de estas características no debe considerarse como una denuncia sobre la situación que expone. Por el contrario, puede ser vista como una gran oportunidad para abordar 
la identificación de esas personas. Si bien recuperar sus identidades demanda un programa amplio de estudios sociales, forenses y judiciales, ahora se cuenta con un diagnóstico riguroso respecto al escenario a encarar. Todo esto apunta pues a reconocer personas, tanto las que reposan en los cementerios, como las que siguen llegando.

En cuanto a estas últimas es importante exponer que se requiere de un conjunto de prácticas adecuadas que favorezcan a posteriori su identificación plena, las cuales se han elaborado a partir del diálogo de saberes entre sepultureros, párrocos, secretarias/os de despachos parroquiales, investigadores sociales y antropólogos forenses. Esta propuesta servirá además para replicarla en el resto del Departamento.

Cuando un cadáver NN es ingresado a un cementerio recorre tres momentos que son la llegada, la permanencia y la salida. Si en cada uno se siguen protocolos apropiados en el manejo, registro y disposición final del cuerpo se contribuye significativamente a la identificación posterior y al trato digno de los NN, que por el hecho de carecer de identidad no los convierte en personas de menor categoría social. A continuación se presentan las variables a tener en cuenta en los momentos mencionados para alcanzar las buenas prácticas.

\subsubsection{La llegada al despacho parroquial:}

- En el despacho parroquial es menester registrar la información precisa sobre el cadáver NN previo a la inhumación en un libro específico, así:

Nombre de la galería o pabellón.

Número de la bóveda.

Fecha de la muerte.

Causa de la muerte.

Lugar de la muerte.

Fecha de inhumación.

Sexo.

Número de necropsia.

Número de certificado de defunción.

Procedencia del cadáver: hospital, medicina legal o fuerza pública.

Funcionario que ordena la inhumación.

- Se recomienda implementar ampliamente el programa informático SIP (Sistema Integral de Parroquias) que utilizan algunas parroquias en el país. Esta herramienta organiza la información sobre el cementerio de manera que permite fácil acceso y manejo por parte de la administración de los mismos. Maneja tres módulos (bóvedas, osarios y cenizarios) en 
ellos se puede consultar fácilmente cuales bóvedas están ocupadas, cuales desocupadas y el destino final de cadáveres exhumados. Sin embargo se requiere que el programa registre de manera individual los NN.

- El cadáver sólo debe ser ingresado al cementerio si hay licencia de inhumación.

- Sólo el despacho parroquial puede autorizar al sepulturero para inhumar un NN, con sustento en una orden de autoridad competente y el documento de soporte por escrito que se debe archivar.

- Conservar el documento de licencia de inhumación en un índice de fácil consulta hasta el momento que la persona sea identificada, sin importar cuántos años tome este proceso.

- Se recomienda al despacho parroquial hacer los registros de manera independiente de las personas NN reconocidas socialmente, es decir, por sus familiares, así como el reconocimiento judicial en caso de darse.

- Se requiere un sistema de registro común de NNs para todas las parroquias sin importar que pertenezcan a diferentes diócesis, puesto que cada una maneja formatos de libros distintos y no tienen la misma política de manejo de los datos y la información. El principal enemigo de los archivos es el desinterés y la falta de voluntad de las instituciones para valorar y conservar la información contenida allí.

- Se supone que en los libros de defunciones sólo se registra a quienes hayan recibido los sacramentos de rigor, si se cobra por parte de la curia central un estipendio por cada registro, entonces desestimula el interés en registrar los $N N$ por quienes nadie paga por sus rituales.

- En fundamental el acompañamiento económico por parte de las administraciones municipales para el buen manejo de los camposantos. En una iniciativa de las alcaldías éstas deberían adquirir el programa SIP para las parroquias que administran cementerios, de manera que tengan la información de NNs unificada, organizada y estandarizada.

- Es importante precisar que el manejo de los cementerios hace parte de la función pública del Estado, y que el hecho de haberlo delegado históricamente en las parroquias no libera a las autoridades de su responsabilidad de control. 


\subsubsection{La llegada al cementerio:}

- El sepulturero debe inhumar cadáveres $N N$ sólo con autorización del despacho parroquial.

- Buena parte de la información de un cementerio reposa en la memoria de los sepultureros y se pierde cuando se retiran de su oficio, por ello es importante conservarla por escrito en un libro de registros de NNs con la siguiente información: nombre de la galería o pabellón, número de la bóveda, fecha de inhumación, sexo y número de necropsia.

- Se debe disponer de bóvedas adecuadas como las de otros difuntos, no utilizar bóvedas en mal estado, con humedades o ubicadas en lugares en ruinas.

- En los cementerios con sepulturas en tierra se debe colocar una placa marcada en el sitio de enterramiento, mantener despejada y demarcada la superficie de las sepulturas, que no queden dependiendo de la buena memoria del sepulturero, y donde puedan ser diferenciadas para futuros eventos de exhumación.

- Los cadáveres NN se inhumarán siempre de manera individual, nunca en grupo.

\subsubsection{La permanencia en el cementerio:}

- Las bóvedas siempre deberán estar marcadas como NN y con fecha de inhumación. Incluso sería ideal que las lápidas tuvieran inscrito el radicado o un código estándar de referencia que ofrece el CTI de la Fiscalía.

- Cuando se realicen labores de mantenimiento como la pintura del camposanto se debe tener cuidado de conservar la misma inscripción sobre las bóvedas de NN. Algunas parroquias no disponen recursos para la compra de pintura y los elementos básicos para ello; en lugar de hacerse una marcación de las tumbas con pintura indeleble, se hace, en algunos casos, sobre cal, que se cae al poco tiempo y desaparece cualquier marca.

- Los cadáveres sin identificar nunca se cambiarán de bóveda a menos que se tenga una orden judicial de la autoridad competente.

- Las parroquias deben promover la identificación de personas que sus familiares conocen que fueron inhumados como NN pero temen hacer la denuncia; esta labor la realizan ante el GIPBDES del CTI en Medellín. 


\subsubsection{La salida de las bóvedas:}

- Se sugiere que los cuerpos de personas sin identificar, que han cumplido los cuatro años de inhumados dentro del cementerio, continúen en sus bóvedas mientras éstas se necesiten para nuevos cadáveres. En caso extremo, se sugiere a la parroquia comunicar el caso al GIPBDES del CTI en Medellín para que programen exhumaciones o se mantengan en custodia los restos en un sitio especial.

- Cuando se realicen exhumaciones por cuenta del CTI o policía judicial la parroquia debe conservar un acta de esa labor.

- Sin la autorización de la fiscalía o de un juzgado no se pueden exhumar los cadáveres sin identificar, ni siquiera para llevarlos a los osarios comunes. Cuando se realice un evento de esta naturaleza, ha de levantarse un acta donde se consigne y especifiquen los procedimientos realizados, las personas e instituciones que intervinieron, el sitio de disposición final y la forma como se individualizaron los restos. De esta manera se podrá exigir, en su momento, la responsabilidad por los hechos ocurridos.

- Ante un caso que requiera el imprescindible traslado de los restos de un NN es obligatorio que se realice a osarios individuales; en ningún caso a osarios comunes. En este caso, los restos se acomodarán en una bolsa de material resistente a condiciones adversas, se identificará con una placa en su interior que registre el número de bóveda de procedencia, fechas de inhumación y de exhumación, sexo y número de la necropsia; además disponer de estos restos en un lugar reconocido y con fácil acceso.

- La diligencia de retiro de un cadáver sin identificar debe registrarse en los libros de defunciones de $\mathrm{NN}$ de la parroquia que administra el cementerio y en el libro de registro de NN del sepulturero. Se debe tener en cuenta que los $N N$ son parte de la memoria histórica de nuestro país. 


\section{Referencias Bibliográficas}

Blair, Elsa. Conflicto armado y militares en Colombia. Cultos símbolos e imaginarios. Editorial Universidad de Antioquia. Medellín. (1999).

Blair, Elsa. Muertes violentas, la teatralización del exceso. Editorial Universidad de Antioquia. (2004). (2007).

CODHESEL. Ejecuciones extrajudiciales, el caso del Oriente antioqueño. Bogotá.

Coordinación Colombia Europa EE.UU. Sin democracia, sin derechos, quinto año de gobierno de Álvaro Uribe Vélez. Bogotá. (2008).

Díaz Faciolince, Victoria Eugenia. Del dolor al duelo: limites al anhelo frente a la desaparición forzada. Universidad de Antioquia. Medellín. (2003).

Mesa de DDHH y Protección Humanitaria del Oriente Antioqueño. Informe sobre la situación de los Derechos Humanos y el Derecho Internacional Humanitario en el Oriente Antioqueño, año 2006. Rionegro. (2007).

Mesa de DDHH y Protección Humanitaria del Oriente Antioqueño. Informe sobre la situación de los Derechos Humanos y el Derecho Internacional Humanitario en el Oriente Antioqueño, año 2007. Rionegro. (2008). (2007).

Observatorio de Paz y Reconciliación del Oriente Antioqueño. Línea de base. Rionegro.

Los desaparecidos forzados en Colombia, ¿̇cuántos se buscan?. En: Hechos del Callejón. Bogotá. Programa de las Naciones Unidas para el Desarrollo, PNUD. № 20. (Noviembre de 2006). 